\title{
Loss of Patency of Major Vessel
}

National Cancer Institute

\section{Source}

National Cancer Institute. Loss of Patency of Major Vessel. NCI Thesaurus. Code C119211.

A decrease in the openness of a major, or great, blood vessel. 